\title{
Correction to: Detection of Abnormal Pressures from Well Logs
}

\section{Correction to:}

Chapter 4 in: T. Dasgupta and S. Mukherjee,

Sediment Compaction and Applications in Petroleum Geoscience, Advances in Oil and Gas Exploration \& Production, https://doi.org/10.1007/978-3-030-13442-6_4

In the original version of the book, Figure 4.10 of Chapter 4 was inadvertently published without proper permission. The Figure has now been replaced with the correct figure after getting permission, and the citations have been added to the reference list. The book and the chapter have been updated with the changes. 